\title{
Fabrication and Characterization of Multiband Printed Antenna with Defective ground Structure Coated with Silver Nanomaterial for Wireless Applications
}

\author{
Ambresh P Ambalgi ${ }^{1}$, Sujata $S K^{2}, P$. V Hunagund ${ }^{3}$ \\ ${ }^{1}$ Department of Electronics, Mangalore University, Mangalore-574199, India. \\ ${ }^{2}$ Department of Electronics Engineering, Sharnbasav University, Kalaburagi-585103. India. \\ ${ }^{3}$ Dept. of Applied Electronics, Gulbarga University, Kalaburagi-585106. India. \\ ambreshpa@gmail.com ${ }^{1}$
}

\begin{abstract}
This paper deals with the study of multiband printed antenna coated with silver nanomaterial to obtain better performace in the antenna characteristics. The techniques adopted in the study are etcing of novel patch with definitive dimensions as the fucntion of chosen operating wavelength at $8 \mathrm{GHz}$ as the design constraint along with defective ground layer to minimize the propogation losses in the antenna. From the results, it is clear that, the antenna obtained $61.20 \%$ improvement in bandwidth for the fabricated Multiband Printed Antenna with Defected Ground Structure (MPA DGS) and 32.10\% bandwidth improvement for Nanomaterial Coated Multiband Printed Antenna with Defected Ground Structure (NCMPA-DGS)(NCMPA-DGS) with quad-band characteristics suitable for Wireless applications. The proposed antennas are compact in nature which has also achieved good radiation characteristics.
\end{abstract}

Keywords: Radiation, Silver, Multiband, Wavelength, Wireless

\section{Introduction}

Microstrip antennas are light, low profile, conformal, compact structures which are normally fabricated on a low cost, low permittivity dielectric substrate. They can be regarded as a dielectric filled parallel plate waveguide radiating at discontinuities $[1,2]$. The size of an antenna can be easily reduced by using a dielectric with a highvalued permittivity but this also increases the energy in the surface wave modes [3]. These surface waves decrease the efficiency of the antenna and also cause interference with the radiation pattern by getting diffracted from the edges of the finite sized ground plane [4]. The multiband resonance is obtained by making appropriate dimensions and spacing among the patches lead to this multi-band response. Although such antennas can also exhibit high gain, they may be not suitable to accommodate inside modern wireless devices. Loading schemes such as inclusion of stubs, shorting pins, and slot cut techniques may yield multi-band operation [5-10]. Main advantage of short and slot loading technique is the miniaturization unlike the stub loading technique. Shorting pins give compactness but have impact on the antenna gain accompanied with high cross polar radiation. The concept of defected ground plane structures (DGS) have gained importance in the antenna design where slots are loaded on the ground to obtain benefits like size reduction, gain enhancement, and frequency tuning [11-16]. The dual and triple band rectangular microstrip antennas employing modified ground plane profiles were the slots are introduced in the ground plane not only tune the higher order mode resonance frequency of the radiating patch but also alter the current distributions on the ground which yields multi-band response showing reduced cross polar level radiation pattern. This Dual and triple band antennas yielded 1 to $2 \%$ of impedance 
www.rspsciencehub.com

bandwidth at each frequency with gain around 1.5 to $2 \mathrm{dBi}$ [17].

2. Design, Fabrication of Multiband Printed Antenna with Defected Ground Structure (MPA DGS) and Nanomaterial Coated Of Multiband Printed Antenna with Defected Ground Structure (NCMPA-DGS)

Fig.1 (a, b \& c) shows the novel Multiband Printed Antenna with Defected Ground Structure (MPA DGS) and Nanomaterial Coated Multiband Printed Antenna with Defected Ground Structure (NCMPA-DGS) are studied. The length and width $(L x W)$ of the MPA DGS is $(8.273 \times 11.410 \mathrm{~mm})$. The MPA DGS has its dimensions as same as that of simple microstrip antenna having length and width of quarterwave transformer $\left(\begin{array}{llll}L_{t} & x & W_{t}\end{array}\right)$ is (4.668 x $0.278 \mathrm{~mm}$ ).

The length and width of microstrip feedline $\left(L_{f} x\right.$ $\left.W_{f}\right)$ is $(4.722 \times 3.058 \mathrm{~mm})$. The various dimensions of I shape patch are $A=2.55 \mathrm{~mm}, B=$ $1.43 \mathrm{~mm}, C=2.86 \mathrm{~mm}, D=2.78 \mathrm{~mm}, E=5.84$ $\mathrm{mm}, F=1.58 \mathrm{~mm}, G=1.96 \mathrm{~mm}, H=2.55 \mathrm{~mm}$. The ground plane of this antenna is etched with plus shape slot of sidelength and width dimension I $x J=1 \times 1 \mathrm{~mm}$ and is called as defected ground structure (DGS) having the dimension in length $L_{g}$ $=20.92 \mathrm{~mm}$ and width $W_{g}=15.71 \mathrm{~mm}$. The same MPA DGS is now uniformly coated with silver nanomaterial which tends to have better conductivity compared to copper layer. The silver nanomaterial is used to enhance its conduction process and to achieve better return loss and better radiation characteristics. This antenna is now called as Nanomaterial Coated Multiband Printed Antenna with Defected Ground Structure (NCMPA-DGS) as shown in Fig. 1 (c).

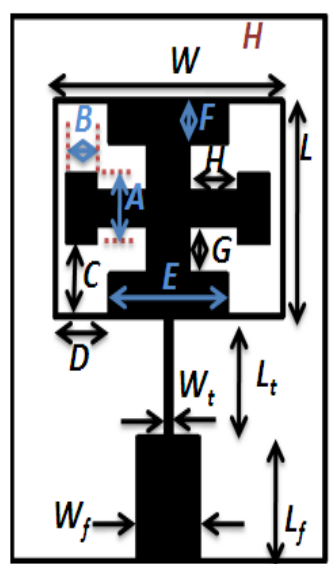

(a)

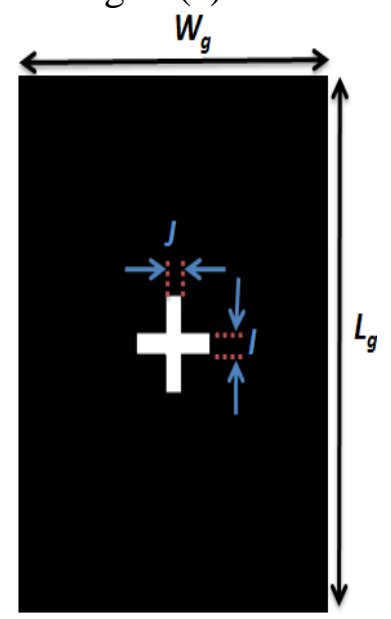

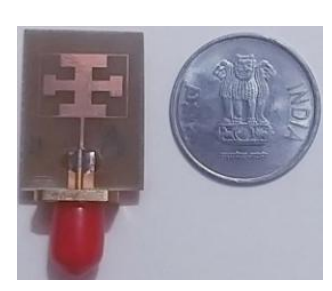

Volume 03 Issue 01 January 2021

(b)
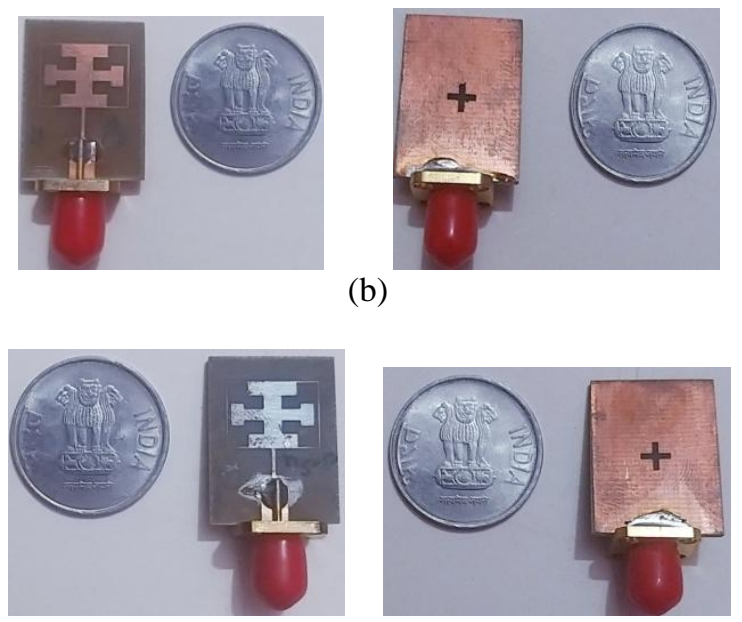

(c)

Fig. 1. a) Geometry of designed Multiband Printed Antenna with Defected Ground Structure (MPA DGS) (front view \& back view)

b) Fabricated Multiband Printed Antenna with Defected Ground Structure (MPA DGS) (front view \& back view)

c) Fabricated Nanomaterial Nanomaterial Coated Multiband Printed Antenna with Defected Ground Structure (NCMPA-DGS) (front view \& back view)

The ground plane of this antenna (NCMPA-DGS) is etched with plus shape slot of sidelength and width dimension $I x J=1 \times 1 \mathrm{~mm}$ and is called as defected ground structure (DGS) having the dimension in length $L_{g}=20.92 \mathrm{~mm}$ and width $W_{g}=$ $15.71 \mathrm{~mm}$. The fabrication the antenna is carried out using photolithography process.

\section{Results \& Discussion (MPA DGS and NCMPA-DGS)}

The variation of return loss verses frequency of MPA DGS is as shown in Fig. 2 (a). From the figure it is clear that, practically the antenna resonates for two band resonances $f r_{1}=5.52 \mathrm{GHz}$ and $f r_{2}=7.8 \mathrm{GHz}$ which are lesser than designed frequency $(8 \mathrm{GHz})$ making it as virtually size reduced with better return loss (RL). From this graph, the bandwidth of MPA DGS are found to be $\mathrm{BW}_{1}=1.1 \%(\mathrm{RL}=-12.41 \mathrm{~dB}), \mathrm{BW}_{2}=61.2 \%$ $(\mathrm{RL}=-18.93 \mathrm{~dB})$. Fig. 2 (b) shows the variation of return loss versus frequency of NCMPA-DGS. This antenna (NCMPA-DGS) is uniformly coated with silver nanomaterial which tends to have better conductivity compared to copper patch. The enhancement in its conduction process and to achieve better return loss, silver nanomaterial is sputtered on both side of patch surface. From this figure it is clear that, the antenna resonates for 
wideband frequency with four independent resonances (wide band) at $f r_{1}=5.5 \mathrm{GHz}, f r_{2}=$ $7.78 \mathrm{GHz}, f r_{3}=10.69 \mathrm{GHz}$ and $f r_{4}=14.77 \mathrm{GHz}$ which are lesser than designed frequency and in close resonance with the MPA DGS making it again a virtually size reduced having better bandwidths with better return loss (RL) characteristics. From this graph, the bandwidth of NCMPA-DGS are found to be $\mathrm{BW}_{1}=0.9 \%(\mathrm{RL}=$ $-12.33 \mathrm{~dB}), \mathrm{BW}_{2}=1.2 \%(\mathrm{RL}=-34.76 \mathrm{~dB}), \mathrm{BW}_{3}=$ $1.8 \%(\mathrm{RL}=-28.05 \mathrm{~dB})$ and $\mathrm{BW}_{4}=32.1 \%(\mathrm{RL}=-$ $42.01 \mathrm{~dB}$ ). (better dip in return loss (RL) making it suitable for wireless application like SAR, RADAR etc.). Fig.2 (c) shows the graph of percentage bandwidth versus frequency comparison of a) MPA DGS, b) NCMPA-DGS For the measurement of radiation pattern, the antenna under test (AUT) i.e., the proposed antennas and standard pyramidal horn antenna are kept in far field region. The AUT, which is the receiving antenna, is kept in phase with respective transmitting pyramidal horn antenna. The power received by AUT is measured from $-0^{0}$ to $+360^{\circ}$ with the steps of $30^{\circ}$. The typical far field co-polar and cross-polar radiating patterns of MPA DGS and NCMPA-DGS are measured in their operating bands are as shown in Fig. $3(a, b)$. From these figures, it can be observed that, the patterns are broadsided (linearly polarized) and unidirectional in nature in $\mathrm{E} \& \mathrm{H}$-planes. Fig.4 $(\mathrm{a}, \mathrm{b})$ shows the FESEM images of fabricated MPA DGS and NCMPA-DGS antennas measured at nanoscale having coat thickness of $2 \mu \mathrm{m}$ and $200 \mathrm{~nm}$ (uniform deposition is seen in the pictures).

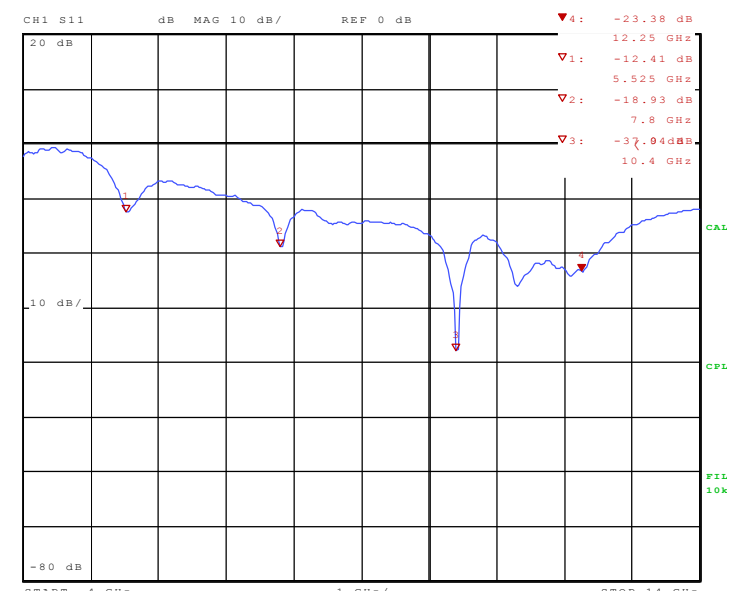

(a)

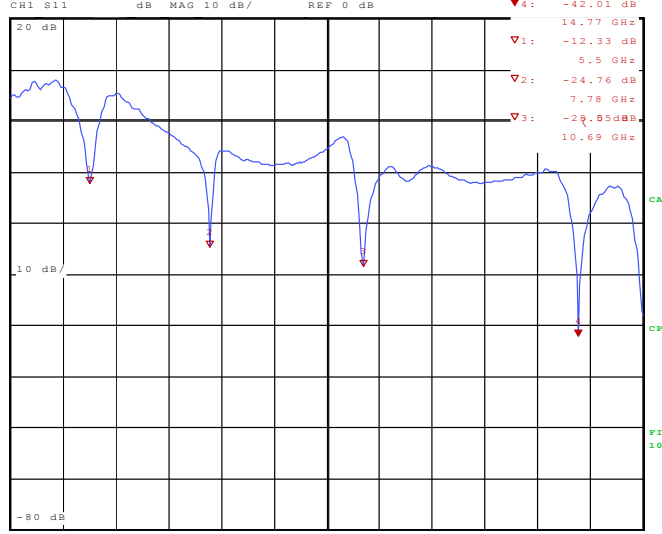

(b)

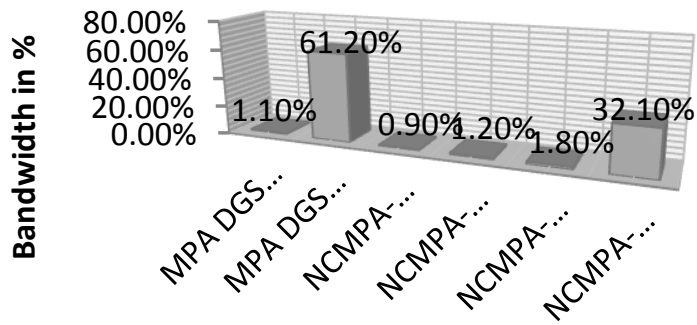

Antenna - Resonant Frequency

(c)

Fig.2. a) Return loss Vs frequency characteristics of MPA DGS, b) Return loss Vs frequency characteristics of NCMPA-DGS c) Bandwidth Vs Frequency comparison of- a) MPA DGS, b) NCMPA-DGS

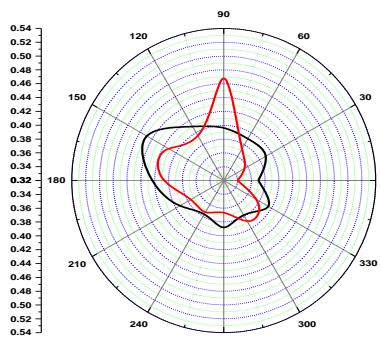

(a)

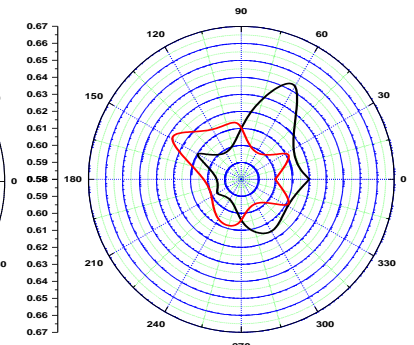

(b)
Fig. 3. Measured radiation pattern of a) MPA DGS, b) NCMPA-DGS

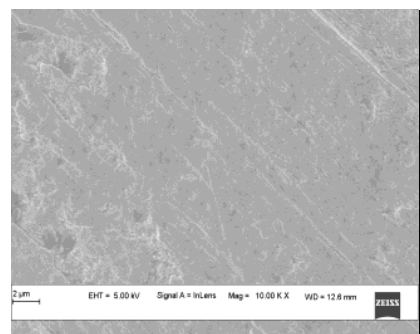

(a)

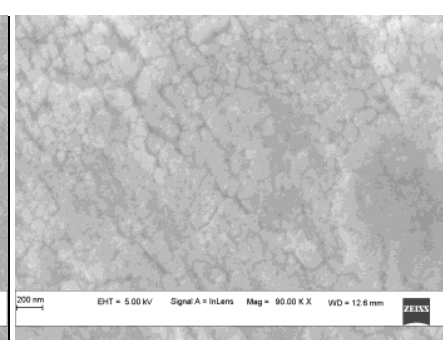

(b)
Fig. 4. FESEM images of a) MPA DGS, b) NCMPA-DGS 


\section{Conclusions}

This paper describes the changes in antenna parameters when its surface is coated silver nanomaterial. The novel printed antennas achieved different responses with better radiation characteristics on coating its surface with nanomaterial. The obtained results also show that the antennas operated differently in presence and absence silver nanomaterial. The proposed novel printed multiband antennas have shown the significant improvement in bandwidth $(61 \%$ for MPA DGS and $32.10 \%$ for NCMPA-DGS), its radiation properties and return loss as compared to normal patch antenna for VSWR $<1.5$.

\section{Acknowledgement (Optional)}

This work is supported by VGST, KSTEPs, Government of Karnataka, India for directing the funds in the form of research grants for scientist faculty (RGS/F) scheme for high microwave frequency band range. Also I acknowledge the support given by the Dept of Applied Electronics, Gulbarga University for providing the facility to use the radiation pattern measurement for X-band range.

\section{References}

[1] Carver, K. and J. Mink, "Microstrip antenna technology," IEEE Transactions on Antennas and Propagation, Vol. 29, No. 1, 2-24, Jan. 1981.

[2] Vaughan, M. J., K. Y. Hur, and R. C. Compton, "Improvement of microstrip patch antenna radiation patterns," IEEE Transactions on Antennas and Propagation, Vol. 42, No. 6, 1980-1983, 1994.

[3] Colburn, J. S. and Y. Rahmat-Samii, "Patch antennas on externally perforated high dielectric constant substrates," IEEE Transactions on Antennas and Propagation, Vol. 47, No. 12, 1785- 1794, 1999.

[4] Jackson, D. R., J. T. Williams, A. K. Bhattacharyya, R. L. Smith, S. J. Buchheit, and S. A. Long, "Microstrip patch designs that do not excite surface waves," IEEE Transactions on Antennas and Propagation, Vol. 41, No. 8, 1026-1037, 1993.

[5] Deshmukh, A. A. and K. P. Ray, "Stub loaded multi-band slotted rectangular microstrip antenna," IET Microwave Antennas Propagation, Vol. 3, No. 3, 3529-535, 2009.

[6] Lee, K., S. Yang, and A. Kishk, "Dual- and multi-band U-slot patch antennas," IEEE Antennas and Wireless Propagation Letters, Vol. 7, 645-647, 2008.

[7] Ollikainen, J., O. Kivekas, A. Tropainen, and P. Vainikainen, "Internal dual-band patch antenna for mobile phones," Millennium Conference on Antennas \& Propagation, 2000.

[8] Esfahlani, S. S., A. Tavakoli, and P. Dehkhoda, "A compact single-layer dual-band microstrip antenna for satellite applications," IEEE Antennas and Wireless Propagation Letters, Vol. 10, 931- 934, 2011.

[9] Saghir, A., S. A. Muzahir, M. U. Afzal, T. Tauqeer, and M. T. Haroon, "Compact dual band microstrip antenna design," IEEE International Conference on Computer, Control and Communication, 2013, 1-4.

[10] Liu, S., S. Qi, W. Wu, and D. Fang, "Singlefeed dual-band single/dual-beam U-slot antenna for wireless communication application," IEEE Transactions on Antennas and Propagation, Vol. 63, No. 8, 3759-3764, 2015. Progress In Electromagnetics Research C, Vol. 100, 202071

[11] Ali, T. and R. Biradar, "A triple-band highly miniaturized antenna for WiMAX/WLAN applications," Microwave Optical Technology Letters, Vol. 60, No. 2, 466-471, 2018.

[12] Kaur, J., R. Khanna, and M. Kartikeyan, "Novel dual-band multi-strip monopole antenna with defected ground structure for WLAN/IMT/BLUETOOTH/WIMAX

applications," International Journal of Microwave and Wireless Technologies, 1-8, 2013.

[13] Yadav, N. P., "Triple U-slot loaded defected ground plane antenna for multi-band operations," Microwave and Optical Technology Letters, Vol. 58, 124-128, 2016.

[14] Arya, A., A. Patnaik, and M. Kartikeyan, "Microstrip patch antenna with Skew-F shaped DGS for dual band operation," Progress In Electromagnetics Research M, Vol. 19, 147-160, 2011.

[15]Li, L., X. Zhang, X. Yin, and L. Zhou, "A compact triple-band monopole antenna for WLAN/WiMAX applications," IEEE Antennas and Wireless Propagation Letters, Vol. 15, 1-3, 2016.

[16] Thomas, K. and M. Sreenivasan, "Compact 
triple-band antenna for WLAN/WiMAX applications," Electronics Letters, Vol. 45, No. 16, 811-813, 2009.

[17] Poonam A. Kadam and Amit A. Deshmukh, Modified Ground Plane Multi-Band Rectangular Microstrip Antennas with Reduced Cross Polar Radiation, Progress In Electromagnetics Research C, Vol. 100, 5971, 2020. 